\title{
Library Services Navigation: Improving the Online User Experience
}

Brian Rennick

\begin{abstract}
While the discoverability of traditional information resources is often the focus of library website design, there is also a need to help users find other services such as equipment, study rooms, and programs. A recent assessment of the Brigham Young University Library website identified nearly two hundred services. Many of these service descriptions were buried deep in the site, making them difficult to locate. This article will describe a web application that was developed to improve service discovery and to help ensure the accuracy and maintainability of service information on an academic library website.
\end{abstract}

\section{INTRODUCTION}

The Brigham Young University Library released a new version of its website in 2014. Multiple usability studies were conducted to inform the design of the new site. During these studies, the web designers observed that when a user did not see what they were looking for on the homepage, they were likely to click on the "Services" link as the next best option. The word services appeared to be an effective catch-all term.

Web designers asked themselves, "What is a library service?" They concluded that a library service could be anything public-facing that meets the needs of a user. Using this broad definition, services could include:

- Library materials - both digital and physical (e.g. books, DVDs)

- Material services (e.g. course reserve, interlibrary loan)

- Equipment and technology (e.g. computers, cameras, tripods)

- Help and guidance (e.g. research assistance, computer assistance)

- Locations (e.g. group study rooms, classrooms, help desks)

- Programs (e.g. Friends of the Library, lectures)

Because libraries offer so many diverse services, structuring a website to effectively promote them all brings many challenges. For instance, a common approach to presenting library services on a website is to have a menu that lists a few of the most popular or important services. The last menu item will normally be a link to a web page for "Other Services" that provides a more

comprehensive service list. Such an all-inclusive listing of library services on a single web page can easily lead to information overload for users.

Where do services belong in a library website's information architecture? Determining the one correct path is not easy because there are multiple valid ways to organize services into web pages. Services could be arranged by department, service category, user group (undergraduates, graduates, faculty, visitors, alumni), or any number of other ways. An ideal system would allow users to follow the path that makes the most sense to them.

Brian Rennick (brian rennick@byu.edu) is AUL for Library IT, Brigham Young University. 
User expectations for a single (Google-like) search box add to the challenges for service listings. ${ }^{1} \mathrm{~A}$ single search box, also known as a metasearch system, web-scale discovery service, or federated search, combines search results from multiple library sources. A study at the University of Colorado found that users expected to locate services by entering keywords into the single search box on the library's homepage. ${ }^{2}$ For example, the users attempted to search for "interlibrary loan" and "chat with a librarian" using the single search box. It is unrealistic to expect all users to follow a specific series of links in order to find the one correct path to information about a service when they are accustomed to Google-style searching.

Even when a user manages to locate the correct web page where a service is described, the pertinent information can still be difficult to pinpoint when service descriptions are buried in paragraphs. Users need to be able to quickly perform a visual scan of a web page to locate service information. Kozak and Hartley suggest that "bulleted lists are easier to read, easier to search and easier to remember than continuous prose." 3

The ongoing maintenance of service listings poses another significant challenge. For large academic libraries, up-to-date service information is difficult to maintain because it is typically scattered throughout a website. Each department may have its own set of web pages and service listings. Department pages created and maintained by different individuals end up with inconsistent design, organization, and voice. Services that are common to multiple departments will have duplicate listings with different descriptions. Maintenance of accurate information becomes an issue as services change; tracking down all of the references to a discontinued or modified service requires extensive searching of the website.

\section{LITERATURE REVIEW}

Studies and commentaries regarding the information architecture of academic library websites have been covered extensively in the literature. ${ }^{4} \mathrm{~A}$ few articles specifically address the way that library services are organized on websites.

Library services are a significant component of academic library website content. Clyde studied one hundred library websites from thirteen countries in order to compare common features and to determine some of the purposes for a library website. ${ }^{5}$ Purposes for the sites varied. Some focused on providing information about the library and its services while others functioned more like a portal, providing links to Internet resources. Cohen and Still developed a list of core content for academic library websites by examining pages from university and two-year college sites. ${ }^{6}$ They organized the content into categories: Library Information, Reference, Research, Instruction, and Functionalities. Liu surveyed ARL libraries to get an overview of the state of web page development. ${ }^{7}$ The subsequent SPEC Kit identifies services commonly found on academic library websites. Yang and Dalal studied a random sample of academic library websites to see which web-based reference services were offered and how they were presented. ${ }^{8}$ They also examined the differing terminology used to describe the services.

The choice of terminology used on library websites impacts the findability of services. Dewey compared academic websites from thirteen member libraries of a consortium to determine how findable service links were on the sites. ${ }^{9}$ The service links used in the evaluation covered "access, reference, information, and user education" categories. The study measured the number of clicks from the homepage that were required to find information about a service. Dewey found 
inconsistent use of terminology used to describe library services from one site to another. Dewey posited that extensive use of library jargon could, in a sense, hide links from users. The overall conclusion was that the websites contained "too much information poorly placed." A study of an academic library website by McGillis and Toms also found that participants struggled with terminology when attempting to locate services. ${ }^{10}$ The website reflected "traditional library structures" instead of using categories that were meaningful to users.

The decision on where to place library services on a website is an important step in the design process. As part of their proposal to establish a benchmarking program for academic library websites, Hightower, Shih, and Tilghman created classifications for the web pages they studied. ${ }^{11}$ Library services were assigned to the "Directional" category instead of representing a separate category. Vaughan described a history of changes to an academic website that took place from 1996-2000. ${ }^{12}$ An interesting change was that, after multiple redesigns, the web designers combined two categories into a single "Library Services" category in order to simplify top level navigation on the home page. Comeaux studied thirty-seven academic library websites to see how design elements evolved between 2012 and $2015 .{ }^{13}$ A portion of the study compiled terms used as navigation labels. The term "About" was the most common navigation label followed by "Services" as the second most common. Use of the term "Services" as a main navigation label increased in popularity from 2012 to 2015.

Several researchers suggest organizing library services into web pages or portals that target different audiences. Gullikson et al. studied usability issues related to the information architecture of an academic website and discovered that study participants followed different paths in their attempts to locate service information on the site. ${ }^{14}$ Some users found items easily while others were unsuccessful. Menu labels were not universally understood. The researchers identified a need for multiple access points to information in order to accommodate different mental models. They suggested employing multiple information organizational schemes, such as categorizing links by function, frequency of use, and target user group. Adams and Cassner analyzed the websites of ARL libraries to see how services for distance education students and faculty were presented. ${ }^{15}$ They recommend strategies for helping distance students navigate the website, including maintaining a web page designed specifically for distance students that avoided jargon and clearly described services. Detlor and Lewis envisioned academic library websites as "sophisticated guidance systems which support users across a wide spectrum of information seeking behaviors - from goal-directed search to wayward browsing."16 They reviewed ARL library websites to see which important features were present or absent. Their coding methodology was adopted by Gardner, Juricek, and Xu in their study of how library web pages can meet the needs of campus faculty. ${ }^{17}$ Liu proposed a conceptual model for an improved academic library website that would be organized into portals designed for specific user groups, such as undergraduates, faculty, or visitors. ${ }^{18}$ Some of the ARL websites studied by the researcher already implemented portals by user group.

A more recent approach for locating library services has been to include website search results when using the single search from the homepage. For example, the North Carolina State Libraries website includes library-wide site search results when using the single search. ${ }^{19}$ The Wayne State University Libraries single search displays results from a university-wide site search. ${ }^{20}$ 
An influential report produced by Andrew Pace provides practical advice for designing library websites. ${ }^{21}$ In the report, Pace described the library services that should be included on a site and stressed that website design affects the discoverability and delivery of these services: "Whether requiring minimal maintenance or constant upkeep, the extensibility of the design and flexibility of a site's architecture ultimately saves the library time, money, hassle, and user frustration."22 The web application described in this article aims to achieve these goals in terms of service discoverability and website maintainability.

\section{A SERVICES WEB APPLICATION}

In an effort to tackle the challenges of services navigation and maintenance, the Brigham Young University Library developed a web application for organizing services that allows multiple routes to service information. The application, known internally as "Services," was built using Django, an open-source Python Web framework. The application incorporates a comprehensive list of library services and a map of service relationships. Each service is assigned one or more categories, locations, and service areas within the application:

- Categories and Subcategories-broad groupings of services (e.g., research help, for faculty, printing and copying)

- Locations-physical or virtual places within the library where services can be found (e.g., help desks, rooms)

- Service Areas - library departments or other organizational units that offer services (e.g., Humanities, Special Collections)

Services can have multiple categories, locations, and service areas and some service areas have multiple locations within the library (see figure 1). Service information can also include links to related services. These links facilitate the serendipitous discovery of additional services (see figure 2). Service information is stored in a relational database that joins connected entities together.

An HTML template is used to format service information from the database in order to generate web pages for each of the services. Maintaining the data in this manner ensures that changes made to service information in the database flow through to all of the associated web pages. Adding or modifying entries automatically triggers the generation of new HTML for only the impacted services. Generating static content by using triggers keeps the web pages up-to-date without the performance hit of real-time dynamic page generation. 


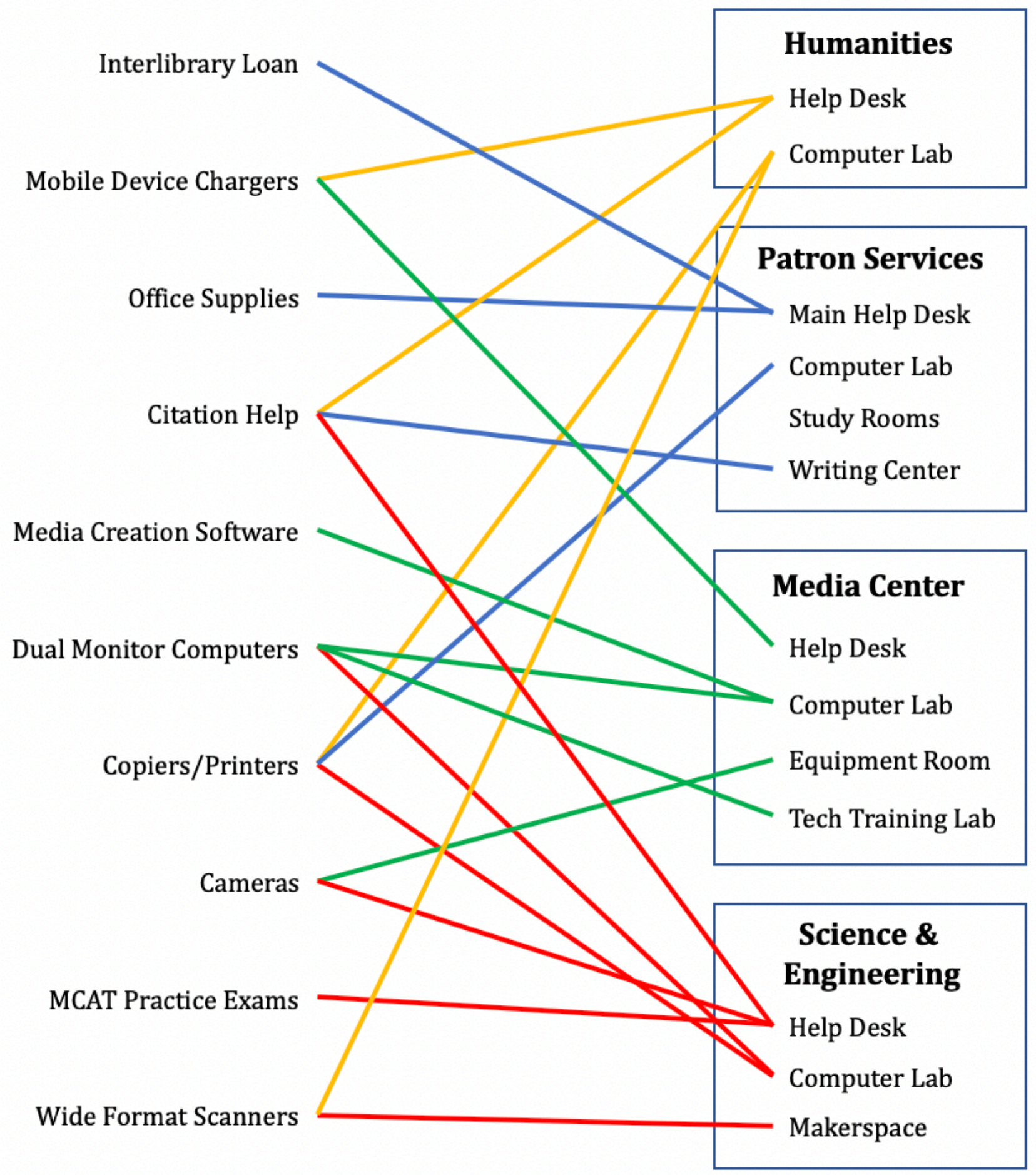

Figure 1. Sample map illustrating relationships between services (on the left side) and service area locations (on the right side). 


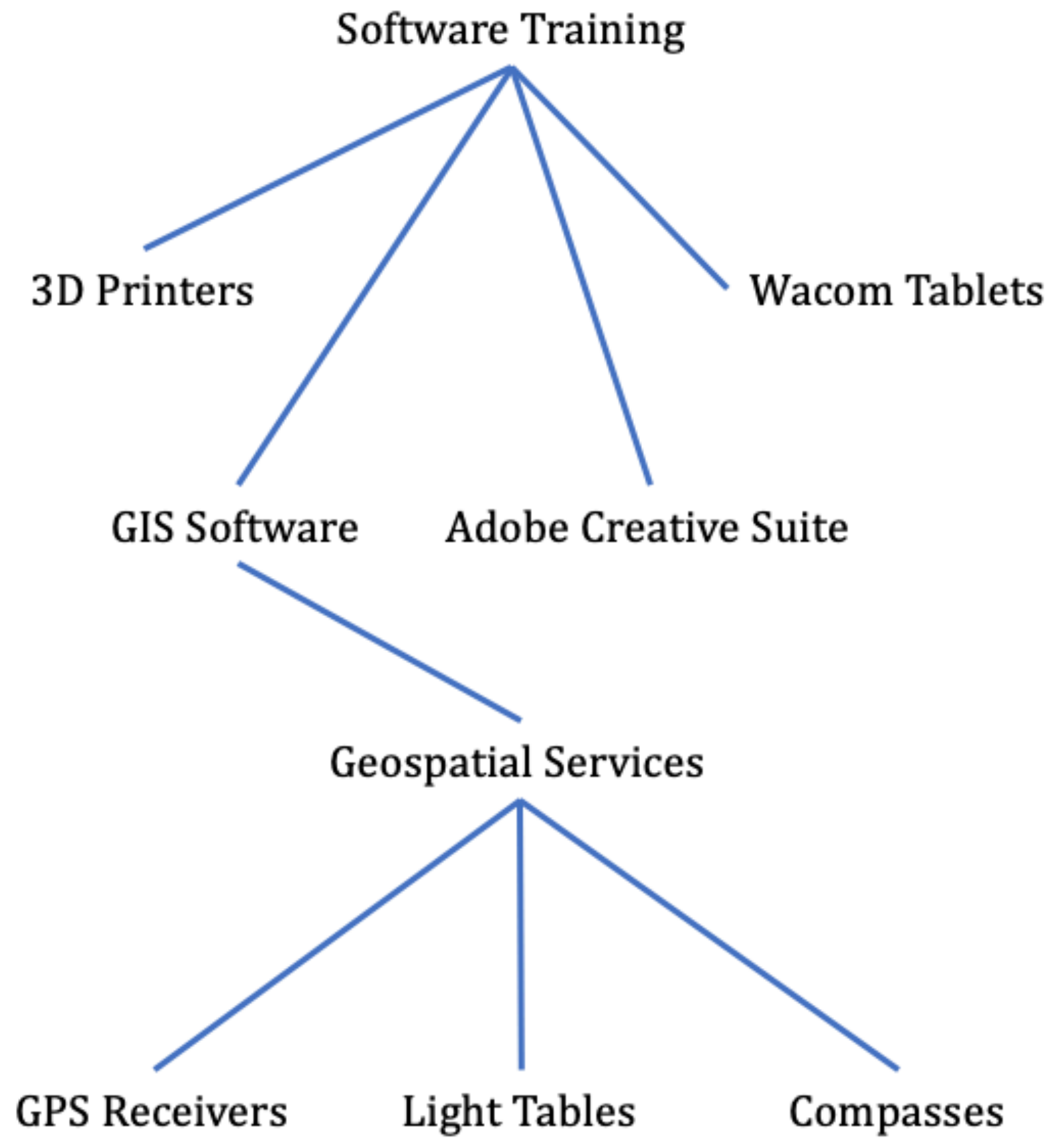

Figure 2. Sample map of how related service web pages are linked. 


\section{USER SCENARIOS}

The following examples of navigation paths typify how the web application can help users locate services. In each case there are multiple alternative paths that could be followed to find the same information.

Scenario 1. A student is looking for a computer that has music notation software installed. Clicking the "Services" link on the library homepage leads to a summary of library services. The student clicks the "Public Computers" link found under the "Featured Services" heading and is presented with detailed information about the computers. In the bullet points listed in the "Overview" section there is a link to "See the list of software available on these computers." Following this link the student is able to learn that the desired software is available in the library's Music and Dance Media Lab.

Scenario 2. While visiting a web page for the faculty delivery service, a professor notices a link to the category "For Faculty." Following the link leads to a page that highlights some of the library services provided exclusively to campus faculty. The professor clicks the link "Faculty Expedited Book Orders" and is taken to a web page that describes the service and provides an online form for requesting a book.

Scenario 3. A student would like to borrow a camera for a class project. Entering "digital cameras" into the main search box on the library homepage produces a link to "Digital Cameras (DSLR)" listed under the "Library Services" heading at the top of the search results. Following the link leads to a web page with information about the library's digital camera offerings. The web page provides links to related services, including the library's video production studio. The student decides to reserve the studio instead of checking out a camera.

\section{ANATOMY OF A SERVICES WEB PAGE}

Each Service web page is divided into sections to help users quickly find the type of information they seek. Each section represents an information module with a specific purpose and an identifying design; the sections are color coded and displayed in a consistent order on each page. This helps users to find the same kind of information in the same place on every service page. Major sections include:

- Title

- Description

- Keywords

- Hours

- Location

- Contact

- Overview

- Call to Action

- Frequently Asked Questions

- Additional Resources

- Related Services

- Categories 
A few of the sections require an explanation. The Hours, Location, and Contact sections are links located directly below the Title and Description. Clicking these links displays the section content. The Overview section is intended to provide brief bullet points near the top of the web page so that users can quickly scan the most important information about the service. The Call to Action section follows these bullet points and contains one or more links to web applications that facilitate use of the service. Examples of calls to action include:

- Place a hold

- Reserve a group study room

- Register for an advanced writing class

- Submit an interlibrary loan request

Most of the sections are optional since not all sections apply to every service. The Services web pages can also include raw HTML that is embedded in a section in order to provide unique formatting for those services that do not neatly fit the standard layout. For example, the Public Computers page includes a section that displays the current availability of computers for each floor of the library.

The look and feel of Services web pages can be extended to other pages on the library website. Library departments have web pages that provide information about personnel, mission, location, and services offered. Some of these pages have been converted to a format that resembles the services layout in an effort to add cohesiveness to the library website. The department pages have sections similar to Services pages such as hours, location, contact information, and an overview with bullet points. The pages can automatically display links to all of the services available in the department. Because department pages are part of the Services application and are connected to services with a relational database, changes to service information remains in sync across the entire website. This helps alleviate the problem of out-of-date department web pages.

\section{SEARCHING FOR SERVICES}

Services can be located by submitting a query in a search box or by following links found on the main Services web page. The Services search engine matches words from the query with words found in a service name or associated tags. Each service is tagged with keywords, phrases, or synonyms to increase the likelihood of successful searching. Users may not be familiar with library jargon and will search for services using a variety of terms. It is impossible to name library services in a way that is understood by everyone, especially since academic library services target both students and faculty. A study on library services and user-centered language found that: "The choices of the graduate students did not always mirror those of the faculty. This highlights the inherent challenge of marketing services-the target audiences for the same service can have very different opinions and preferences." ${ }^{23}$

Services can have multi-word phrases assigned in addition to individual keywords. For example, the data management service has the following synonyms assigned: data curation, data management plan, and DMP. New keywords and phrases can be identified by reviewing search queries in the system log files and by conducting usability studies. 


\section{Interlibrary Loan}

If the Library doesn't have what you're looking for, Interlibrary Loan will get it for you

(1) Hours $\odot$ Location Contact

Overview

Frequently Asked Questions

Additional

Resources
Borrow almost anything from other libraries for free (books, DVDs, CDs, scores, maps, microfilm, periodicals, newspapers, etc.)

Get articles and book chapters as PDFs for free

Delivery of Library items to Distance Education patrons (usually Independent Study students)

Pick up requested items at the Circulation Desk

Faculty can have books delivered to their department offices

\section{Submit a request}

, What is interlibrary loan?

How do I make an Interlibrary Loan request?

Where do I pick up and return my interlibrary loan book?

When should I expect my Interlibrary Loan book to arrive?

See all FAQs

Worldcat (use to search for items to order through Interlibrary Loan)

Lending to Other Libraries Policy

Figure 3. The interlibrary loan service web page. 
In addition to using a search box on the Services web pages, users can search for services using the single search box on the library's homepage. The single search box returns a link to matching services as part of search results when the search engine recognizes services keywords in a query. The Services application has an API that makes keywords and other service information available to the single search box application.

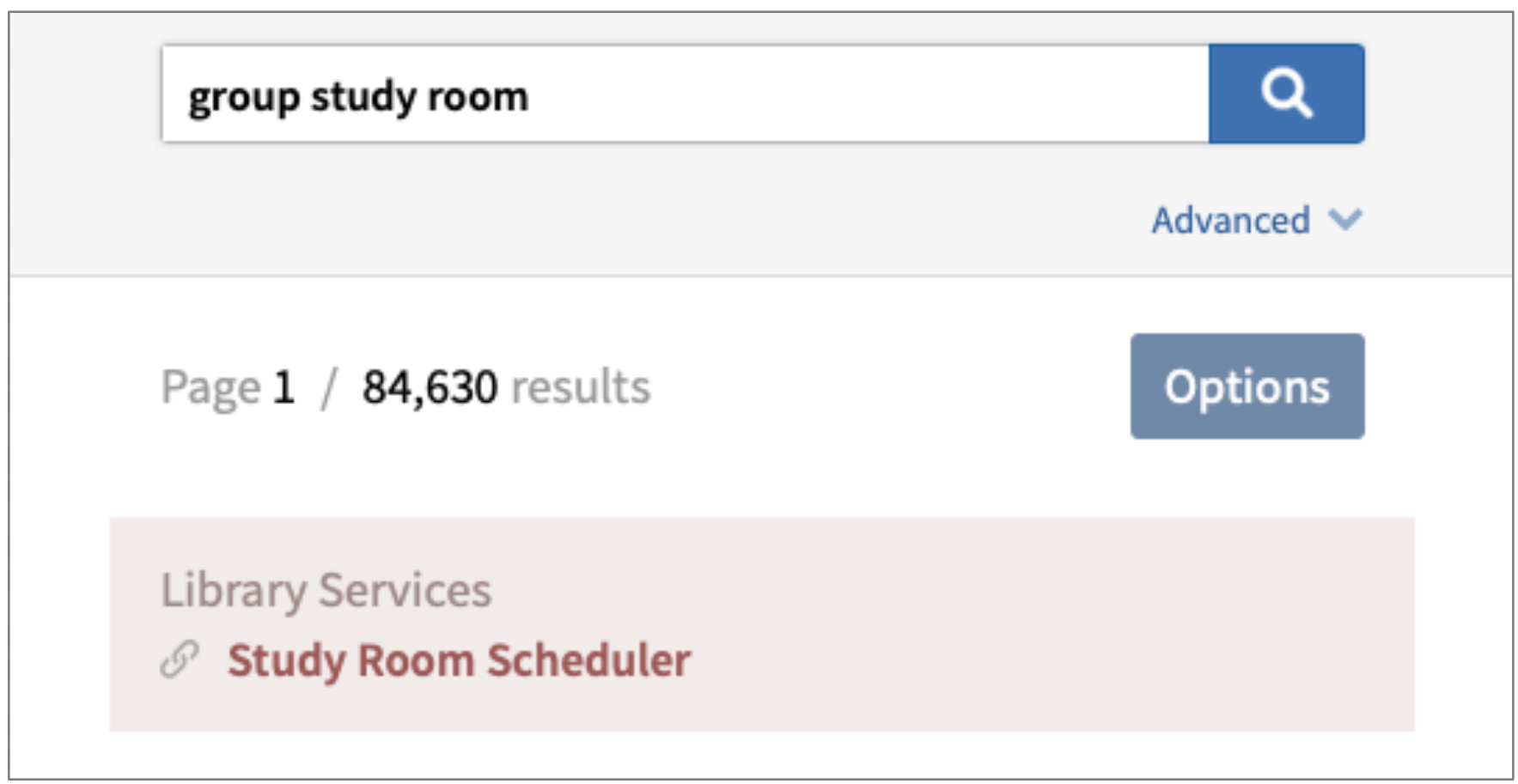

Figure 4. Search for a service from the single search box on the library's homepage.

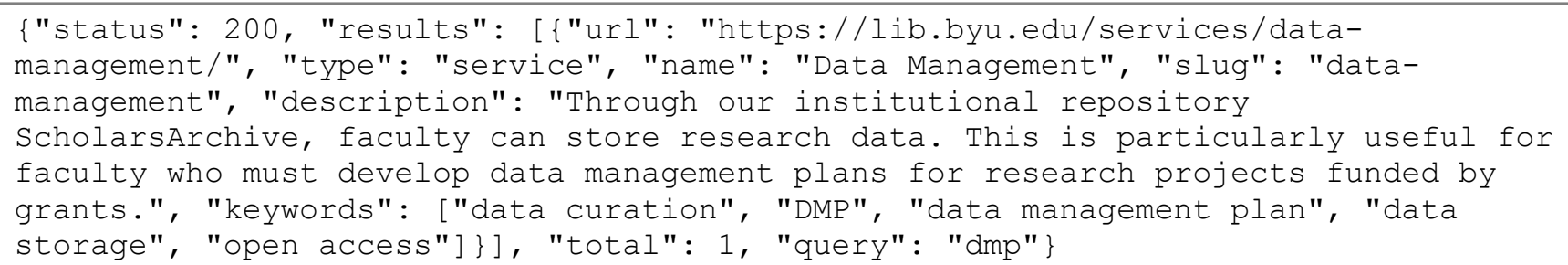

Figure 5. JSON results from the Services API.

To facilitate browsing, services are organized into three groups on the Services web page:

Featured Services, Categories, and Service Areas. The Featured Services group highlights the most commonly sought-after services. Categories are organized by the type of service or the target audience. The Service Areas group directs users to services available in library departments or units. The Services web page does not list every service but instead directs users to web pages based on categories or service areas that list individual services.

The Services search feature can also include links to non-services. For example, library policies are not services yet users occasionally search for them on the Services page (the library website posts 
policy documents on the About page). In order to minimize user frustration with searching, links to non-services are included in search results so that users can be redirected to the desired pages.

To help with optimization for external search engines such as Google, each Services page has a user-friendly URL that clearly identifies the service. For example, the 3D printer service has the URL https://lib.byu.edu/services/3d-printers/. Each web page also includes the service name in an embedded HTML title tag.

\section{CONCLUSION}

Adopting a broad view of what represents a service has altered the library's approach to the information architecture of the website. The Services web application offers several innovations for improving library service discoverability and maintenance including:

- Standardized organization of service information

- Attaching keywords/aliases to service descriptions

- An API for integration with the single search box on the homepage

- Links to related services

- Generation of web pages from a relational database

Usability tests were conducted throughout the development of the Services application. Follow-up assessments are planned for the future in order to verify that the application works as expected and to identify potential adjustments to the design. The Services application shows promise as an effective tool for facilitating the discovery of services and increasing the reliability and uniformity of service information.

\section{ACKNOWLEDGEMENTS}

The author gratefully acknowledges the contributions of Grant Zabriskie for the original concept and design of the Services application and Ben Crowder for the implementation.

\section{REFERENCES}

${ }^{1}$ Cory Lown, Tito Sierra, and Josh Boyer, "How Users Search the Library from a Single Search Box," College \& Research Libraries 74, no. 3 (May 2013): 227-41, https://doi.org/10.5860/crl-321.

2 Rice Majors, “Comparative User Experiences of Next-Generation Catalogue Interfaces," Library Trends 61, no. 1 (Summer 2012): 186-207, https://doi.org/10.1353/lib.2012.0029.

${ }^{3}$ Marcin Kozak and James Hartley, "Writing the Conclusions: How Do Bullet-Points Help?" Journal of Information Science 37 no. 2 (Feb. 2011): 221-24, https://doi.org/10.1177/0165551511399333.

${ }^{4}$ Barbara A. Blummer, “A Literature Review of Academic Library Web Page Studies," Journal of Web Librarianship 1 no. 1 (2007): 45-64, https://doi.org/10.1300/I502v01n01 04; Galina Letnikova, "Usability Testing of Academic Library Web Sites: A Selective Annotated Bibliography," Internet Reference Services Quarterly 8 no. 4 (2004): 53-68, https://doi.org/10.1300/】136v08n04 04. 
${ }^{5}$ Laurel A. Clyde, "The Library as Information Provider: The Home Page," The Electronic Library 14 no. 6 (Dec. 1996): 549-58, https://doi.org/10.1108/eb045522.

${ }^{6}$ Laura B. Cohen and Julie M. Still, “A Comparison of Research University and Two-Year College Library Web Sites: Content, Functionality, and Form," College \& Research Libraries 60 no. 3 (1999): 275-89, https://doi.org/10.5860/crl.60.3.275.

7 Yaping Peter Liu, “Web Page Development and Management: A SPEC Kit," Association of Research Libraries (1999): https://hdl.handle.net/2027/mdp.39015042087232.

${ }^{8}$ Sharon Q. Yang and Heather A. Dalal, "Delivering Virtual Reference Services on the Web: An Investigation into the Current Practice by Academic Libraries," Journal of Academic Librarianship 41 no. 1 (2015): 68-86, https://doi.org/10.1016/i.acalib.2014.10.003.

${ }^{9}$ Barbara I. Dewey, "In Search of Services: Analyzing the Findability of Links on CIC University Libraries' Web Pages," Information Technology and Libraries, 18 no. 4 (1999): 210-13, http://www.ala.org/sites/ala.org.acrl/files/content/conferences/pdf/dewey99.pdf.

${ }^{10}$ Louise McGillis and Elaine G. Toms, "Usability of the Academic Library Web Site: Implications for Design," College \& Research Libraries 62 no. 4 (July 2001): 355-67, https://doi.org/10.5860/crl.62.4.355.

${ }^{11}$ Christy Hightower, Julie Shih, and Adam Tilghman, "Recommendations for Benchmarking Web Site Usage among Academic Libraries," College \& Research Libraries 59 no. 1 (Jan. 1998): 61-79, https://crl.acrl.org/index.php/crl/article/viewFile/15182/16628.

12 Jason Vaughan, “Three Iterations of an Academic Library Web Site," Information Technology and Libraries 20 no. 2 (June 2001): 81-92, https://search.proquest.com/docview/215832160.

${ }^{13}$ David J. Comeaux, “Web Design Trends in Academic Libraries-A Longitudinal Study,” Journal of Web Librarianship 11 no. 1 (2017): 1-15, https://doi.org/10.1080/19322909.2016.1230031.

${ }^{14}$ Shelly Gullikson et al., "The Impact of Information Architecture on Academic Web Site Usability," The Electronic Library 17 no. 5 (Oct. 1999): 293-304, https://doi.org/10.1108/02640479910330714.

15 Kate E. Adams and Mary Cassner, "Content and Design of Academic Library Web Sites for Distance Learners: An Analysis of ARL Libraries," Journal of Library Administration 37 no. 1/2 (2002): 3-13, https://doi.org/10.1300/J111v37n01 02.

${ }^{16}$ Brian Detlor and Vivian Lewis, “Academic Library Web Sites: Current Practice and Future Directions," Journal of Academic Librarianship 32 no. 3 (May 2006): 251-58, https://doi.org/10.1016/j.acalib.2006.02.007.

${ }^{17}$ Susan J. Gardner, John Eric Juricek, and F. Grace Xu, "An Analysis of Academic Library Web Pages for Faculty," Journal of Academic Librarianship 34 no. 1 (Jan. 2008): 6-24, https://doi.org/10.1016/j.acalib.2007.11.006. 
${ }^{18}$ Shu Liu, "Engaging Users: The Future of Academic Library Web Sites," College \& Research Libraries 69 no. 1 (Jan. 2008): 6-27, https://doi.org/10.5860/crl.69.1.6.

${ }^{19}$ Kevin Beswick, "QuickSearch," North Carolina State University Libraries, accessed Nov. 28, 2018, https://www.lib.ncsu.edu/projects/quicksearch.

${ }^{20}$ Cole Hudson and Graham Hukill, "One-To-Many: Building a Single-Search Interface for Disparate Resources," in Exploring Discovery: The Front Door to Your Library's Licensed and Digitized Content, ed. Kenneth J. Varnum (Chicago: ALA Editions, 2016), 141-53, http://digitalcommons.wayne.edu/libsp/114.

${ }^{21}$ Andrew K. Pace, "Optimizing Library Web Services: A Usability Approach," Library Technology Reports 38 no. 2 (Mar./Apr. 2002): 1-87, https://doi.org/10.5860/ltr.38n2.

${ }^{22}$ Ibid.

${ }^{23}$ Allison R. Benedetti, "Promoting Library Services with User-Centered Language," Libraries \& The Academy 17 no. 2 (Apr. 2017): 217-34, https://doi.org/10.1353/pla.2017.0013. 